\title{
Correction to: Revising Pharmacokinetics of Oral Drug Absorption: II Bioavailability-Bioequivalence Considerations
}

Pavlos Chryssafidis 1,2 • Athanasios A. Tsekouras ${ }^{3,1}$ • Panos Macheras 1,2

Published online: 28 September 2021

(C) Springer Science+Business Media, LLC, part of Springer Nature 2021

Correction to: Pharmaceutical Research volume 38, pages I345-I356 (202 I). https://doi.org/I 0.1007/s I 1095-02 I-03078-w

Table IV of this article has been updated.

The original article has been corrected.

Publisher's Note Springer Nature remains neutral with regard to jurisdictional claims in published maps and institutional affiliations.

The online version of the original article can be found at https://doi.org/l 0 . 1007/s | | 095-02 I-03078-w

Panos Macheras

macheras@pharm.uoa.gr

Pharmalnformatics Unit, Research Center ATHENA, Athens, Greece

2 Faculty of Pharmacy, Laboratory of Biopharmaceutics Pharmacokinetics, National and Kapodistrian University of Athens, Athens, Greece

3 Department of Chemistry, Laboratory of Physical Chemistry, National and Kapodistrian University of Athens, Athens, Greece 